\title{
BIOÉTICA, SABER NARRATIVO Y SENTIDO DE VIDA
}

\author{
Hernando Barrios Tao ${ }^{1}$, Manuel Losada Sierra²
}

\section{Resumen}

Introducción: Humanismo y vida continúan en proceso de reconfiguración en el ágora digital. En las últimas décadas, se ha consolidado un "movimiento narrativo" con presencia de la bioética en esta ola. El presente artículo se orienta a plantear que el mundo de la vida y su sentido podrían encontrar en el saber narrativo elementos para fortalecer una bioética en crisis en su camino hacia los 50 años. Metodología: Artículo de reflexión con base en una revisión narrativa focalizada en las categorías bioética, saber narrativo, hermenéutica, vida, en bases de datos internacionales y autores representativos. Resultados: El saber narrativo con su poder performativo, su fuerza configuradora de realidad, sentido e identidad y su dimensión hermenéutica podrían fortalecer los procesos de la bioética. La estructura del relato, forma privilegiada del saber narrativo, posibilita plantear implicaciones y provocaciones para la bioética. Conclusiones: La bioética podría caminar de analizar principios a reconfigurar sus propuestas mediante la hermenéutica de la vida misma y su sentido, con la mediación del saber narrativo.

${ }^{1}$ Profesor titular. Doctor en Teología. Coordinador Doctorado en Bioética, Facultad de Educación y Humanidades, Universidad Militar Nueva Granada. Bogotá, Colombia.

2 Profesor asociado. Doctor en Filosofía. Facultad de Educación y Humanidades, Universidad Militar Nueva Granada. Bogotá, Colombia. 


\title{
BIOETHICS, NARRATIVE KNOWLEDGE AND LIFE SENSE
}

Hernando Barrios Tao, Manuel Losada Sierra

\begin{abstract}
Introduction. Humanism and life continue in a remaking process in the digital agora. In the last years, it has been consolidated a narrative wave whit bioethics participation. This paper evidence that the life environment and its sense could find in narrative knowledge elements for strengthen a bioethics on the way to his 50 years. Methodology. Perspective, opinnion and commentary paper based on a narrative review focused on the categories of bioethics, narrative knowledge, hermeneutics and life, based on international database searches and outstandig authors. Results. The narrative knowledge with if performative power, reality-shaping force, sense and identity and its hermeneutic dimension, could strengthen bioetics process. The structure of the story, privileged form of narrative knowledge, it allows implications and provocations for bioethics. The bioethics could change from analyze axioms to reconfigurate proposals through hermeneutics of life itself and his sense, whit the mediation of narrative knowledge.
\end{abstract}




\title{
BIOÉTICA, SABER NARRATIVO E SENTIDO DE VIDA
}

\author{
Hernando Barrios Tao, Manuel Losada Sierra
}

\section{Resumo}

Introdução: o humanismo e a vida continuam o processo de reconfiguração na ágora digital. Nas últimas décadas, tem sido consolidado um "movimento narrativo" com presença da bioética neste movimento. O presente artigo, orienta-se a considerar que o mundo da vida e seu sentido podem-se encontrar no saber narrativo, assim os elementos para fortalecer uma bioética em crises em seu caminho para cinquenta. Metodologia: artigo de reflexão em base de uma revisão narrativa focalizada nas categorias bioética, saber narrativo, hermenêutica, vida, em base de dados internacionais e autores representativos. Resultados: o saber narrativo com seu poder performativo, sua força configuradora de realidade, sentido e identidade, sua dimensão hermenêutica pode fortalecer os processos da bioética. A estrutura do relato, forma privilegiada do saber narrativo, possibilita considerar-se implicações e provocações para a bioética. Conclusões: a bioética poderia caminhar e analisar os princípios a reconfigurar suas propostas por meio da hermenêutica da vida mesma e seu sentido, com a mediação do saber narrativo. 


\section{Introducción}

La bioética marca su rumbo con el sello de la crisis en su camino hacia los 50 años. En el ámbito de la medicina, la crisis se vincula con el panorama de la deshumanización: "No obstante los esfuerzos del cultivo de la sensibilidad y humanidad no se han rendido los frutos esperados, perdiendo importancia y presencia en un mundo pragmático concentrado en eficiencia y cumplimiento de metas" (1). Kottow retoma un espectro más amplio: "Incompetencia filosófica" (Savulescu), "irrelevancia social" (Hedgecoe) (1) y excesos académicos: "una elaborada disquisición teórica y un esfuerzo por esquematizar y sistematizar la aplicación práctica de la reflexión bioética con recurso a principios cuya primacía es permanentemente sometida a ratificación o crítica" (2).

Frente a la "bioética desafiante" de Savulescu que exige claridad, precisión y coherencia $(3,4)$, la "bioética complaciente" de Kass ampara bajo un supuesto consenso toda práctica, por discutible que pareciese en un momento (5). Este funcionamiento ministerial y "complaciente" puesto al servicio de intereses institucionales, gubernamentales, sustentados en declaraciones y leyes, denota también un estancamiento de la bioética en formas legales: "los ideólogos del actual Estado, más que buscar súbditos, lo que pretenden es encontrar cómplices" (6).

Esta situación no se desliga de la crisis de las humanidades, que no solo afecta su relevancia social $(7,8)$, sino también aspectos educativos, pedagógicos y políticos (9-14). Contextos y tecnologías novedosas, así como dinámica en los enfoques de las humanidades, parecieran ser suficientes para sustentar su crisis como compañera permanente y necesaria (15). La crisis no excluye la responsabilidad de algunos humanistas debido a su modo particular de labor investigativa, diversidad conceptual y posición en las instituciones universitarias (16-18) y de otros bioeticistas convertidos en "justificadores sofisticados de todo cuanto la comunidad científica desea hacer" (19).

Humanismo, vida, saber, continúan en proceso de reconfiguración en los escenarios de la sociedad tecnológica. Subjetividades y sentido de vida esperan respuestas urgentes y marcan retos a la bioética (20). Más allá del principialismo, éticas de segundo y tercer orden indican a la bioética la necesidad de ofrecer respuestas al sentido de la vida misma, su relación con el otro y con la supervivencia en la aldea global, retada con el sello de las tecnologías. Las respuestas no se pueden reducir a discusiones relacionadas con expresiones, bioética hermenéutica, bioética social, bioética ecológica, bioética narrativa o narrativa bioética sino que las respuestas deben ir más allá, al sentido mismo de la vida como tarea fundamental de la bioética.

La supuesta reconfiguración del estatuto mismo del humanismo no solo recoge cuestionamientos a la naturaleza, condición e identidad del ser humano. Cyborg, hombre postorgánico, hombre numérico, hombre simbiótico, cyberanthropos, son términos que cuestionan las otrora dimensiones del ser humano: finitud, corporeidad, contingencia, racionalidad. Dignidad, naturaleza, condición, fundamento y sustento de algunos principios 
de la bioética ya no tienen consenso y no tienen cabida en algunas bioéticas principialistas, son cuestionadas y se someten a juicios críticos para considerar su validez y aprobación (20).

El artículo de reflexión se sustenta en una revisión narrativa delimitada por las categorías bioética, narrativa, hermenéutica, vida, en bases de datos internacionales $\mathrm{y}$ análisis de autores representativos del saber narrativo. La reflexión se centra en la relación bioética y saber narrativo bajo la óptica del poder performativo de la narración, su fuerza configuradora de realidad, sentido e identidad y su dimensión hermenéutica, elementos que podrían fortalecer la bioética. A manera de conclusiones, se plantean implicaciones y provocaciones que el saber narrativo propone a la bioética, a partir de la estructura del relato como su forma privilegiada.

\section{Saber narrativo, hermenéutica y mundo de la vida}

Saber narrativo se contextualiza en la sociedad tecnológica cuyo desarrollo ha generado la reconfiguración del estatuto del conocimiento, visible en expresiones como chips de conocimiento, saber-poder, saber-estado, "inteligencia colectiva" (21), "multitudes inteligentes" (22), saber social: "la cuestión del saber en la edad de la informática es más que nunca la cuestión del gobierno" (23). Saber narrativo supera la condición cognitiva y arriba a las habilidades de comprender, historizar, analizar, reflexionar, conmemorar, interpretar, configurar. En este sentido, los aspectos propuestos por Lyotard y el relato como la forma por excelencia de ese saber: 1) permiten definir criterios de competencia que son los de la sociedad donde se cuentan y valorar las actuaciones; 2) admiten pluralidad de juegos del lenguaje (enunciados denotativos, deónticos, interrogativos, valorativos); 3 ) se transmiten como una pragmática intrínseca al relato que no es universalizable; 4 ) tienen incidencia sobre el tiempo (23).

En las últimas décadas se ha consolidado un "movimiento narrativo" (historia, causas, autores) en diferentes escenarios de la aldea y en diversos ámbitos (educación, pedagogía, investigación, formación), la bioética no se ha ausentado de esta "ola": “Espuma de los días agitada por los medios de comunicación, o bien ola de fondo procedente de los confines de la historia de la humanidad suscitada por el declive de los grandes discursos que dan sentido a la existencia y a las agitaciones múltiples de una revolución bio-ética?" (24). El saber narrativo ha incursionado en la medicina (25-28) con una doble formulación. Por un lado, como una competencia narrativa cuyos desempeños permiten reconocer, interpretar y dejarse interpelar emocionalmente por las historias de vida de los enfermos, y por otra con un enfoque más personal, como una redefinición radical de la relación médico-paciente en la cual las historias de vida de los enfermos ocupan el centro de la práctica médica (29).

El saber narrativo se constituye en una de las puertas de entrada a la construcción de realidad y al mundo de la vida. Para Bruner, no hay otro modo de describir el "tiempo vivido" y capturar su sentido salvo en la forma narrativa. Más aún, la narrativa imita la vida y la vida imita la narrativa. "Vida", en este sentido, es el mismo modo de construcción de la 
imaginación humana, como lo es "una narrativa" (30). Penetrar y auscultar la vida ha sido una pasión humanista de todos los tiempos: los griegos no disponían de un término único para expresar lo que entendemos por la palabra vida. Se servían de dos palabras: zoé, que expresaba el simple hecho de vivir, común a todos los seres vivos (animales, hombres o dioses) y bios, que indicaba la forma o la manera de vivir propias de un individuo o de un grupo (31).

Frente a la dimensión cientificista y al paradigma lógico-científico, las voces de reclamo "para comprender lo humano (Ortega y Gasset) e incluir el mundo de la vida (Husserl)", sin hacer abstracción de los sujetos en cuanto personas con una vida personal (32), interpelan tanto a procesos bioéticos como a propuestas investigativas: "La narrativa no es sólo una metodología (...) es una forma de construir realidad, por lo que la metodología se asienta, diríamos, en una ontología” (32).

El saber narrativo dimensiona los fenómenos sociales en su configuración como textos, cuyo valor y significado viene dado por la hermenéutica realizada por los actores (33): "Los fenómenos sociales (y, dentro de ellos, la educación) como 'textos', cuyo valor y significado, primariamente, vienen dados por la autointerpretación que los sujetos relatan en primera persona, donde la dimensión temporal y biográfica ocupa una posición central" (32). Esta forma propia para caracterizar las acciones humanas en el ámbito de la investigación hermenéutica se orienta a "dar sentido y a comprender (frente a 'explicar' por relaciones causas-efectos) la experiencia vivida y narrada” (34):
Una de las grandes aportaciones del paradigma hermenéutico es haber puesto de manifiesto el carácter narrativo de la experiencia humana. Si la experiencia humana es narrativa, tiene estructura narrativa, la racionalidad que dé cuenta de lo humano tendrá que contar con lo narrativo. Por eso ya no nos vale una razón especulativa u objetiva y tenemos que apostar por una razón narrativa, hermenéutica, vital, o contextual (muchas formas, pues, de referirnos a lo mismo) (35).

En el contexto posterior a la modernidad se percibe una crisis de los modos paradigmáticos establecidos de conocer, donde se replantea el papel del sujeto investigador y la necesidad de incluir la subjetividad en el proceso de comprensión de la realidad. Tanto el mundo de la vida como las mismas situaciones humanas se podrían describir con mayor integridad y hasta caricaturizar con el "medium por excelencia" del saber narrativo, el relato (32). La narrativa no solo "subjuntiviza" la realidad, sino que su capacidad arriba al punto de "modelar" los conceptos de realidad y legitimidad (36).

Para considerar la relación mundo de la vida y relato, más allá de la mímesis (imitación de la acción), debemos buscar con Ricoeur "los puntos de apoyo que el relato puede encontrar en la experiencia viva (...) lo que en esta experiencia viva requiere la inserción de lo narrativo y quizá expresa la necesidad del mismo" (37):

El primer anclaje que encontramos para la inteligibilidad narrativa en la experiencia viva consiste en la estructura misma del actuar y del sufrir humanos. A este respecto, la vida humana difiere 
profundamente de la vida animal y con mayor motivo de la existencia mineral. El segundo anclaje que la proposición narrativa encuentra en la comprensión práctica reside en los recursos simbólicos del campo práctico. Característica que va a decidir qué aspectos del hacer, del poder-hacery del saber-poder-hacer son resultado de la transposición poética. El tercer anclaje del relato en la vida consiste en lo que se podría llamar la cualidad pre-narrativa de la experiencia humana. Es gracias ella que tenemos el derecho a hablar de la vida como una historia en estado naciente y, por lo tanto, de la vida como una actividad y una pasión en busca de relato (37).

Relato, historia y ficción son categorías que se entrecruzan en el saber narrativo y se materializan en el tejido o intriga que "constituye la fuente creadora del relato" (37) y en el que convergen sus peripecias: "la trama tiene la virtud de obtener una historia a partir de sucesos diversos o, si se prefiere, de transformar los múltiples sucesos en una historia" (37). Sucesos encadenados bajo la dinámica causa-efecto, espacio y tiempo (38) con la presencia mágica de la ficción, son los aspectos fundamentales que determinan el relato (39). Estos aspectos son fundamentales no solo para la comprensión del mundo de la vida, sino para considerar la bioética en relación con el sentido de la vida misma.

El proceso de composición y de configuración del relato no se acaba en el texto, sino en el lector, cuya experiencia podría ser transfigurada mediante el análisis del relato: "la construcción de la trama es la obra común del texto y el lector", de ahí que "el sentido o el significado de un relato surge en la intersección del mundo del texto con el mundo del lector" (37) (39).

\section{Saber narrativo, subjetividad y sentido de vida}

Las deliberaciones bioéticas, sustentadas en el sentido de la misma vida, no pueden desatender dos tópicos que determinan la categoría subjetividad. Por una parte, "en el sentido de proceso de formación, constitución del sujeto, construcción del yo en un contexto (tiempo y espacio)" y, por otra, "su relación con un macro-contexto o complejo social, cultural, político con tensiones y contradicciones" (40). El contexto digital o cibercultura marca un "proceso de co-construcción" e incidencia mutua entre transformación tecnológica con el ser, hacer y pensar de las subjetividades (40), hasta el punto de la modificación de la textura misma de la vida (41), la incidencia en la vida (42), con la necesidad apremiante de ofrecer respuestas no solo a las nuevas maneras de estar en el mundo, sino también al sentido de la vida y del vivir en estos nuevos contextos.

Del mundo de la vida y los procesos sociales como textos, el saber narrativo se focaliza en la vida misma como texto, bajo la relación simple entre historia y vida, reducida al espacio vital entre nacimiento y muerte (37), dos límites objeto de incertidumbre en los acercamientos bioéticos contemporáneos. El espacio vital del ser humano es necesario también someterlo a "duda crítica" en relación con su configuración y sentido. La vida en busca de relato o "la vida: un relato en busca de narrador" (37) es una provocación en la relación vida-relato, 
cuando se acepta la vida como texto: "Lo que es necesario poner en cuestión, es la ecuación demasiado simple entre vida y vivido. Una vida no es más que un fenómeno biológico en tanto la vida no sea interpretada” (37). Más aún, “a esta relación entre relato y vida, quisiera aplicar la máxima de Sócrates según la cual una vida no examinada no es digna de ser vivida" (37).

Los procesos bioéticos relacionados con la hermenéutica de la vida implican la pregunta “¿Qué es una vida narrada?”, la respuesta podría ser simple si no se consideran sus consecuencias: "Es una vida en la cual encontramos todas las estructuras fundamentales del relato (...) $y$, sobre todo, el juego entre concordancia y discordancia que nos pareció caracterizar el relato" (37). Más aún, si el proceso de composición, de configuración del relato no se acaba en el texto sino en el lector, la conclusión no solo es que el sentido o el significado de un relato surge en la intersección del mundo del texto con el mundo del lector, sino que bajo esta condición es posible la reconfiguración de la vida por el relato (37): "La narración es una forma de producir sentido, de crear imágenes, de establecer síntesis. Y allí donde hay sentido - que puede ser múltiple- puede haber ambigüedad, y, por tanto, hay hermenéutica. La hermenéutica se define así como interpretación del sentido, interpretación de la narración, de las metáforas, de los símbolos" (35).

La dimensión performativa marca el punto central del relato en relación con la búsqueda de sentido, configuración de subjetividad y construcción de identidad. Tanto el mismo narrador que relata su vida, como el lector que participa en la interpretación se entrecruzan en un horizonte de sentido en el mundo del relato. La formación de identidad, reflejada en la relación consigo, con los otros y con el entorno, se configura en los relatos construidos y actuados que se convierten en textos con los cuales se expresa y orienta el sentido dado a la vida. Así, con Bruner y Weiser se puede afirmar sin ambages que "las vidas son textos susceptibles de revisión, exégesis, reinterpretación" (43) y, por el contrario, "sin la capacidad de contar historias sobre nosotros mismos no existiría una cosa como la identidad" (36).

Recuerdos del pasado, experiencias del presente y expectativas del futuro determinan la construcción y reconstrucción permanente de sentido que dinamizan tanto el sentido como la reflexión, significado y valoración del mundo de la vida y de los diferentes avatares que la retan, dinamizan y maduran (44). Así, la dimensión performativa del relato se sustenta en su definición como "una particular reconstrucción de la experiencia, por la que, mediante un proceso reflexivo, se da significado a lo sucedido o vivido" (44). De manera particular, la historia de vida "se inscribe en una investigación vital de saber-poder vivir, como una práctica formadora de existencia más o menos corriente, más o menos consciente, más o menos formalizada" (24) y con tres tipos de saber ligados con su desarrollo; saber, saber-hacer y saber-ser (45).

Foucault crea una "estética de la existencia" a partir de la concepción griega del cuidado de sí (épiméleia eauto) (46), en consonancia con la concepción acerca de las personas como lectoras y escritoras 
de su propio vivir. Por su parte, Passeggi plantea un segundo principio de la narrativa autobiográfica como elemento mediador de la construcción de la "historicidad del sujeto": "Al interpretar la vida, el sujeto no niega un texto anterior, pero sí su interpretación. Al transformar su vida en un texto narrativo, el sujeto crea una versión provisional de sí mismo, que hasta entonces no existía" (43). En esta línea, la vida como un texto se abre a las dimensiones de lo mental, lo escrito, lo narrado, y lo hablado, a través de lo cual se devela un Yo oculto-Yo narrado-Yo proyectado-Yo deseado (47).

En relación con el vínculo vida-relato, texto-vida, Ricoeur plantea lo que denomina una paradoja: "las historias se narran, la vida se vive", de lo cual "un abismo parece abrirse entre la ficción y la vida” (37). Sin embargo, esta paradoja se disuelve cuando se considera el planteamiento en el sentido inverso: tanto las historias como las vidas se viven y se narran. En este sentido, el mismo Ricoeur propone una triple mímesis relacionada con el desarrollo de subjetividad y construcción de sentido (39):

Mímesis I (pre-figuración): las comprensiones y experiencias previas que el lector y el autor de un texto tienen sobre la acción humana como un curso en el tiempo, y que se transmiten a través de los símbolos culturales compartidos. Mímesis II (configuración): la construcción literaria de una trama, a través de un relato desarrollado temporalmente sobre la historia de una vida. Mímesis III (refiguración):la aplicación del relato a la propia vida, construyendo un nuevo mundo u horizonte de sentido (48).

\section{Saber narrativo y bioética: implicaciones y provocaciones}

El puente hacia el futuro propuesto por Potter sugiere una "nueva sabiduría" con dos ingredientes: conocimiento biológico (bío) y valores humanos (ética) (49), que podría recibir del saber narrativo un aporte, además de reconfigurar las relaciones entre Atenas y Jerusalén, mediante las categorías phrónesis y $\mathrm{hkm}$ respectivamente: "Debemos, sin embargo, hablar de inteligencia, pero en el sentido que Aristóteles daba a la phrónesis (que los latinos tradujeron por prudentia). En este sentido, hablaré de inteligencia phronética en oposición a la inteligencia teórica. El relato pertenece a la primera clase de inteligencia y no a la segunda" (37). Algunas implicaciones y provocaciones (bajo la acepción de estimulación y promover reacción), se podrían considerar en la relación saber narrativo y bioética, a través de la óptica de los aspectos fundamentales que identifican y estructuran el relato.

\section{A partir de la condición espacio-tem- poral que no extrapola la ficción}

La primera implicación provocadora para la bioética es la orientación del saber narrativo y su mediación el relato hacia la dimensión espacio-temporal (39). De manera específica, conducen el bíos, la vida y su sentido, a la condición fundamental del ser humano: ser histórico. El juego narrativo enmarcado entre la vida y la muerte ha caracterizado la historia de la condición humana. Animal cultural y biológico, con la posibilidad de ex-centricidad (50), confieren a la condición humana orientar su sentido, con una hodierna reacción en los trans y 
poshumanismos: ¿la crisis de sentido no trazaría una ruta de incomprensión de la condición humana y un escape hacia su reconfiguración con el pretexto de mejorarla y aun de superarla?

Considerar el ser humano y su vida sin extrapolar su realidad socio-histórica tiene el potencial de reconfigurar al individuo, y en última instancia, abordar de forma íntegra el ser humano (48), más allá de principios abstractos que no pocas veces consideran el sentido de la vida excluida de tiempo y espacio. Las vicisitudes de las intenciones humanas, objeto de la narrativa (33) y necesarias para las deliberaciones bioéticas podrían abordarse con el relato y su capacidad de captar la riqueza y detalles de los significados en los asuntos humanos (motivaciones, sentimientos, deseos o propósitos) que no pueden ser expresados en definiciones, enunciados factuales o proposiciones abstractas, como hace el razonamiento lógico formal (32). La racionalidad histórica y la pretensión de razón objetiva no solo han colapsado $(51,52)$, sino que han orientado la búsqueda del sentido del mundo de la vida en la experiencia ubicada en la historicidad y fragilidad del ser humano:

Ante la frustración colectiva, histórica, (...) se focaliza nuestra atención hacia la condición incierta, contingente y finita de la experiencia humana, desechando la fe moderna en el fundamento racional y lo racionalmente fundado. El contextualismo sitúa cada hecho en su marco específico, sin aspirar a una verdad universal que lo trascienda. Las "narrativas locales" muestran el lado
Una antropología narrativa podría contribuir a fortalecer el sentido de la vida al no extrapolar aquellos elementos humanos descuidados por muchos bioeticistas con la consecuente deshumanización de algunos saberes relacionados con la bioética, la medicina, la educación, la psicología: "Frente a una antropología metafísica (o de la substancia), una antropología narrativa sostiene que para los seres humanos no existen referencias definitivas o absolutas, sino solamente 'soportes' provisionales, frágiles y ambiguos, ubicados en el tiempo y en el espacio, en la historia, en la tradición" (50).

Una antropología narrativa provoca reacción frente a algunas antropologías metafísicas abstractas sustentadoras de principialismos con peligro de considerar el ser humano, centro de la bioética, con la supuesta mirada objetiva de "principios absolutos establecidos a priori que nos digan de manera objetiva, fija y definitiva, lo que está bien o lo que está mal” (50). Saber narrativo relacionado con el ser humano, con sus vicisitudes, vulnerabilidades y posibilidades, inevitables para su sentido del mundo de la vida, implica una antropología narrativa en la que "los seres humanos aparecen como seres «de carne y hueso", hombres y mujeres que nacen, sufren y mueren, que no tienen otro remedio que resolver a cada instante, hic et nunc, lo que quieren hacer con sus vidas. Dicho de otro modo, somos seres 'adverbiales', 'condicionales', que andamos decidiendo "sobre el terreno», en situación" (50).

La provocación frente a bioéticas principialistas radica en que la condición espacio-temporal del saber narrativo 
implica aspectos subjetivos y desafíos a "las suposiciones implícitas de veracidad" (53): “donde hay 'narración' hay flujo, hay cambio, hay transformación, hay ambigüedad, hay ambivalencia” (50). La bioética no podría detenerse en aspectos que salvaguarden principios y refieran aspectos metafísicos como la esencia, substancia, identidad, dignidad, descuidando la vida misma con su dimensión socio-histórica, sustento de deliberaciones humanas conducentes que respondan por qué somos lo que somos o, todavía mejor, cómo hemos llegado a ser lo que somos ("proceso de identificación») y cómo podemos vivir, es decir, una antropología narrativa que sea una antropología del arte de vivir (50).

La hermenéutica marca la narración tanto en su construcción como en su comprensión (38). El mundo de la vida historizado clama por una orientación hermenéutica que trace la ruta para abordar la complejidad del mundo de la vida, para orientar la búsqueda de sentido y para la comprensión del otro $(54,55)$. Las voces de algunos bioeticistas han asumido esta tercera implicación y han socializado sus propuestas, todavía con tímidas respuestas: "La vida es compleja, difícil, incierta, ambigua, y pide un método adecuado a estas características. De igual forma, si la ética habla de la vida y quiere orientar la vida de alguna manera tendrá que convertirse en hermenéutica" $(35,56)$.

La relación hermenéutica y bioética es una llamada para caminar más allá de principios hasta llegar a la complejidad de la condición humana: "Los grandes principios universales y abstractos, por su generalización, distorsionan la comprensión de las acciones concretas y particu- lares. Una hermenéutica narrativa, por el contrario, permite la comprensión de la complejidad psicológica de las narraciones que los individuos hacen de los conflictos y los dilemas en sus vidas" (47). El desafío para la bioética es arribar a los "horizontes" desplegados en el mundo de la vida: el mundo del lector (mundo del lector-médico) y el mundo del texto (mundo del autor-texto-narrativa, enfermo). Esta "fusión de horizontes" (57), clave para la tarea hermenéutica, supera diagnósticos y consentimientos informados institucionalizados y despersonalizados para llegar a la hermenéutica de los textos (el mundo de la vida del enfermo) y traspasar hasta el límite de lo que Bolívar denomina la "hermenéutica de la vida humana" (47).

Esta sabiduría narrativa que se acerca al texto (enfermo, mundo de la vida) implica para los bioeticistas considerar el texto bajo tres dimensiones: referencialidad "entre el hombre y el mundo", comunicabilidad "entre el hombre y el hombre", comprensión "entre el hombre y sí mismo". En la hermenéutica estas dimensiones se configuran con nuevas características: referencialidad no descriptiva, comunicabilidad no utilitaria, reflexividad no narcisista: "En una palabra, la hermenéutica sostiene el gozne entre la configuración (interna) de la obra y la refiguración (externa) de la vida" (37).

La narrativa tiene el poder extraño de combinar historia y ficción. En la ética no es extraño considerar la capacidad del ser humano para entrar en el mundo de la imaginación (58) y la utilidad práctica de los "métodos imaginativos" para comprender aspectos éticos en medicina $(59,60)$. La definición sencilla del relato, 
modo como se cuenta una historia, indica esta dimensión creativa, de ahí que el relato "explore las situaciones humanas mediante el prisma de la imaginación" (36). El mundo de la vida, aquello que trasciende el mismo ser humano, sentimientos, sentido, no puede ser expresado sino con la imaginación simbólica, el mito y el relato $(59,60)$.

Más allá de apuestas por dilemas éticos acerca de la vida su sentido y desarrollo, la provocación para la bioética es fortalecer la "capacidad pre-narrativa de lo que llamamos una vida" (37). En la base del saber narrativo acerca de las respuestas a los problemas del mundo de la vida y de la vida misma, está el sentido mismo de la vida que es necesario poner en cuestión, "es la ecuación demasiado simple entre vida y vivido. Una vida no es más que un fenómeno biológico en tanto la vida no sea interpretada" (37). La referencia de Kottow vincula esta ficción narrativa con la bioética médica: "El imaginario narrativo sabe retratar una medicina 'humanizada' con más prestancia que la desgastada estrechez de visión y tendencia a conservadurismo de la bioética (Brody, 2009, p. 40)" (1).

\section{A partir de la construcción de la intriga, acciones bajo la dinámica causa-efecto}

Autor-lector-intriga es el triángulo mediante el cual el texto narra e interpreta la vida. En la construcción de la historia de vida, autor y lector se subsumen en el tejido que traza el relato, mediante el cual bio-ética y biopolítica postmoderna que traslada la dialéctica bio-lógica desde arriba hacia abajo" (24) que remite a los individuos la tarea de construir sentido con su vida:

El sentido de la vida ya no está dado prioritariamente por la aplicación de leyes religiosas o científicas; debe ser construido por la expresión de los vivientes que movilizan la reflexión y la formación de signos. El movimiento biográfico se inscribe en el paso del paradigma de la ciencia aplicada al del práctico reflexivo, introduciendo las temporalidades largas, personales, sociales, intergeneracionales, e incluso cósmicas (24).

De ahí que más allá de escenarios académicos, comités o élites, entrar la vida en la historia es un ejercicio, según Pineau (24), para "todos los que desean hacerse cargo de su vida". Este movimiento de entrada es doble y ambivalente: "Es el de todas las vidas, pero también el de todos los vivientes (...) El movimiento de biografización actual de la vida se inscribe a nuestro juicio en el paso de un segundo umbral, postmoderno, de modernidad biológica, de una revolución bio-ética y biopolítica, que traslada a los individuos la tarea de construir el sentido de sus vidas":

Las historias de vida favorecen la exploración del mundo personal desde una perspectiva libre y subjetiva, en un marco interpersonal (Lainé, 1998, Cornejo, 2006). Enfrentan al sujeto con sus conflictos y favorecen una resolución positiva de los mismos, en la perspectiva de lo que Ricoeur ha llamado una memoria feliz. Son una vía de acceso al trabajo pedagógico experiencial, subjetivo, 
afectivo y rememorativo. Propician una dinámica de apertura, comunicación profunda y colaboración, posibilitan la expresión de los sentimientos, a la vez que sensibilizan al sujeto hacia los sentimientos de los demás, aumentando la empatía y la tolerancia (55).

\section{Conclusiones}

En la era digital, la relación vida-tecnología-sentido ha pasado de la ficción que superaba la realidad, a la realidad más extraña que la fantasía y la realidad superando la ficción, con desafíos y provocaciones para la bioética con la exigencia de respuestas aún más urgentes. Historia y ficción trazan la dialéctica entre lo que se esperaba y lo que sucedió, desafían la concepción de lo canónico y llegan a ser instrumento no tanto para resolver problemas cuanto para encontrarlos, para prevenir, con mucha más frecuencia, que instruir.

El saber narrativo implica considerar la vida en un contexto socio-cultural y ubicar su sentido en un marco personal-histórico, lo cual lleva a comprender los problemas bioéticos como relatos inscritos en un contexto cultural y en un marco personal, que forman parte de un modo de ver el mundo.

Vulnerabilidad, fragilidad, emociones, sentimientos, marcan la condición humana como horizonte no solo de comprensión deliberativa, sino ante todo de fundamentación para abordar el sentido del mundo de la vida, tarea de la bioética y una segunda implicación provocadora para los bioeticistas. En el fondo, se marca el desafío de una antropología orientada también por el saber narrativo, sustentada por la sabiduría que se materializa en el relato, y en la cual subyace la comprensión del ser humano con su dimensión socio-histórica.

Hermenéutica y cientificidad todavía se mueven en la dicotomía de las ciencias naturales y las ciencias de la vida. Una bioética que no se desprenda de su "condición ministerial” y de su pretensión de resolver conflictos en los escritorios médicos y en algunos eminentes comités y tribunales de aplicación de principios, seguirá ahondando su crisis.

La formación de subjetividades implica, además de la constitución y desarrollo del sujeto, la dimensión relacional del mundo del otro y de lo otro. Esta perspectiva dialógica es propia también del saber narrativo en cuanto que allí se fusionan los horizontes del texto, el autor y el lector. Para la bioética se abre una nueva provocación y para la medicina una tarea: los principios no pueden obnubilar la comprensión del otro, posible gracias a la posibilidad de expresión, escucha y verbalización del mundo y el sentido de su vida.

\section{Agradecimientos}

El artículo se asocia con el proyecto de investigación "INV-HUM-2359: Narrativa, memoria y formación para la convivencia en el ámbito educativo universitario. Fase 1", financiado por la Universidad Militar Nueva Granada, Colombia. 


\section{Referencias}

1. Kottow M. ¿Bioética narrativa o narrativa bioética? Revista Latinoamericana de Bioética. 2016; 16(31):58-69.

2. Kottow M. La enseñanza de una bioética proximal. Revista Latinoamericana de Bioética. 2015; 15(29):14-25.

3. Savulescu J. ¿Decisiones peligrosas? Una bioética desafiante. Madrid: Tecnos; 2012.

4. Álvarez I. La bioética desafiante de J. Savulescu. Dilemata. 2014; 15:69-92.

5. Kass L. The Wisdom of Repugnance. The Human Life Review. 1997; 23(3):6388.

6. Serrano J. Blog de bioética y libertades públicas. Eutanasia. Nicolás Gómez Dávila. Pensamiento reaccionario. Democracia y Nihilismo [en línea]; 2017 [citado 2017 Marzo 15. Disponible en: "http://josemiguelserrano.blogspot.com.co/2011/05/ politica-de-estado-al-final-de-la-vida. html" V "more" http://josemiguelserrano. blogspot.com.co/2011/05/politica-de-estado-al-final-de-la-vida.html\#more .

7. Hedgecoe A. Critical bioethics: beyond the social science critique of applied ethics. Bioethics. 2004; 18(2):120-143.

8. Maldonado C. Crisis of Bioethics And bioethics in the midst of crises. Revista Latinoamericana de Bioética. 2012; 12(1):112-123.

9. Sierra R. ¿Por qué aún humanidades? In Sierra R. Ensayos impopulares. Manizales: Universidad de Caldas; 2002.

10. Kagan J. The Three Cultures: Natural Sciences, Social Sciencies and the Humanities in the 21 st. Century Cambridge:
11. Nussbaum M. Sin fines de lucro, Por qué la democracia necesita de las humanidades Madrid: Katz Editores; 2010.

12. Unesco. El Informe sobre las ciencias sociales en el mundo. Las brechas del conocimiento México: Unesco; 2011.

13. Montaño, J. R. et al. La enseñanzaaprendizaje de las humanidades en el siglo XXI: Retos y perspectivas Educación Md, editor. La Habana: Editor Educación Cubana; 2011.

14. Llovet J. Adiós a la Universidad. El eclipse de las humanidades Barcelona: Galaxia Gutenberg; 2012.

15. Barrios-Tao H, Parra O, Siciliani, JM. Educación y ágora digital: retos y horizontes para la formación humanística. El Ágora USB. 2015; 15(1):169-193.

16. Hall S. The Emergence of Cultural Studies and the Crisis of the Humanities. October. 1990; 53:11-23.

17. Lye C, Newfield C, Vernon J. Humanists and the Public University. Representations. 2011; 116(1):1-18.

18. Di Leo J. This Humanities Which Is Not One. Symploke. 2012; 20(1):319-325.

19. Fukuyama F. El fin del hombre. Consecuencias de la revolución biotecnológica. Barcelona: Ediciones B; 2002.

20. Barrios-Tao H. Subjetividades en el ágora digital: Cuestiones para la educación y la bioética. Revista Latinoamericana de Bioética. 2015; 15(2):84-95.

21. Lévy P. Inteligencia colectiva. Por una antropología del ciberespacio: Organización Panamericana de la Salud; 2004.

22. Rheingold $\mathrm{H}$. Multitudes inteligentes. La próxima revolución social. Barcelona: Gedisa; 2004. 
23. Lyotard JF. La condición postmoderna: Informe sobre el saber. Madrid: Cátedra; 2004.

24. Pineau G. Las historias de vida como artes formadoras de la existencia. Cuestiones Pedagógicas. 2008; 19(1):247-265.

25. Charon R. Narrative Medicine, A model for Empathy, Reflection, Profession, and Trust. Journal of American Medical Association. 2001; 286(15):1897-1902.

26. Charon R. Narrative Medicine: Honoring the Stories of Illness. New York: Oxford University Press; 2006.

27. Charon R, DasGupta S, Hermann N, Irvine C, Marcus E, Rivera E, Spencer D, Spiegel M. The Principles and Practice of Narrative Medicine. New York: Oxford University Press; 2017.

28. Fuks A, Kreiswirth M, Boudreau D, Sparks T. Narratives, Metaphors, and the Clinical Relationship. Genre. 2011; 44(3): 301-313.

29. Goupy F. La médecine narrative. Une révolution pédagogique. Paris: Med-Line Editions; 2017.

30. Bruner J. Life as Narrative. Social Research. 2004; 71(3):691-710.

31. Agamben G. Homo Sacer. Vol. I Le Pouvoir souverain et la vie nue. Paris: Seuil; 1997.

32. Bolívar A. ¿De nobis ipsis silemus?: Epistemología de la investigación biográfico-narrativa en educación. Revista Electrónica de Investigación Educativa. 2002; 4(1).

33. Bruner J. Realidad mental, mundos posibles. Barcelona: Gedisa; 1988.

34. McEwan H, Egan K, editors. La narrativa en la enseñanza, el aprendizaje y la investigación. Buenos Aires: Amorrortu Editores; 1997.
35. Domingo Moratalla T. Bioética y hermenéutica. La aportación de Paul Ricoeur a la bioética. Veritas. Revista de Filosofía y Teología. 2007; II(17):281-312.

36. Bruner J. La fábrica de historias. Derecho, literatura, vida. Buenos Aires: Fondo de Cultura Económica; 2003.

37. Ricoeur P. La vida: un relato en busca de narrador. Agora. 2006; 25(2):9-22.

38. Bruner J. The Narrative Construction of Reality. Critical Inquiry. 1991; 18:1-21.

39. Ricoeur P. Narratividad, fenomenología y hermenéutica. Anàlisi. 2000; 25:189-207.

40. Amador JC. Aprendizaje transmedia en la era de la convergencia cultural interactiva. Educación y Ciudad. 2013; 25:1124.

41. Bernal A. Postmodernización y educación. Notas para el debate de una narrativa pedagógica centrada en la identidad. Educación. 2011; XXI(14.2):285-302.

42. Negroponte N. El mundo digital. Barcelona: Ediciones B; 1995.

43. Passeggi M. Aproximaciones teóricas a las perspectivas de la investigación (auto) bio gráfica en educación. Revista Educación y pedagogía. 2011; 23(61):25-40.

44. Ricoeur P. Tiempo y narración. Vol . II. Configuración del tiempo en el relato de ficción. México: Siglo XXI; 1995.

45. Burrick $D$. Une épistémologie du récit de vie. Recherches qualitatives-Hors Série. 2010; 8:7-36.

46. Foucault M. Hermenéutica del sujeto. Madrid: Ediciones de la Piqueta; 1987.

47. Bolívar A, Domingo J, Fernández M. La investigaión biográfico-narrativa en 
educación. Enfoque y metodología. Madrid: Editorial La Muralla S.A.; 2001.

48. Feito L. Bioética narrativa. Butlletí del comitè de bioètica de Catalunya. 2013;(9).

49. Mazzeo M. La cura della vita. Bibbia e bioetica. Bologna: Edizioni Dehoniane Bologna; 2015.

50. Mélich JC. Antropología narrativa y educación. Teor. Educ. 2008; 20(1):101-124.

51. Horkheimer M. Crítica de la razón instrumental: medios y fines. Madrid: Trotta; 2002.

52. Perdue L. The Collapse of History: Reconstructing Old Testament Theology. Minneapolis: Fortress Press; 1994.

53. Conle C. The Rationality of Narrative Inquiry in Research and Professional Development. European Journal of Teacher Education. 2001; 24(1):21-33.

54. Fernández O, Ocando J. La comprensión del otro a partir de las historias de vida. Telos. Revista de Estudios interdisciplinares en ciencias sociales. 2006; 8(1):94-105.

55. González J. Historias de vida y teorías de la educación: Tendiendo puentes. Encounters on Education. 2007; 8:85-107.

56. Dubiel H. What is "Narrative Bioethics". Frontiers in Integrative Neuroscience. 2011; $5(10)$.

57. Gadamer H. Verdad y método. Salamanca: Sígueme; 1993.

58. Aranguren J. Ética. Madrid: Alianza Editorial; 1990.

59. Agich G. The Salience of Narrative for Bioethics. American Journal of Bioethics. 2001; 1(1).

60. Anderson C. Narrative in Bioethics. American Journal of Bioethics. 2001; 1(1): 61-62. 